\title{
INDEPENDENT DISCOVERY IN BIOLOGY: INVESTIGATING STYLES OF SCIENTIFIC RESEARCH
}

\author{
by \\ NICHOLAS RUSSELL *
}

\section{INTRODUCTION}

The fact that discoveries are often made independently is a commonplace of the history and sociology of science. Analysis of independent discovery has potential for evaluating the relative importance of social and individual components in the conduct of scientific research. ${ }^{1}$ For instance, in a classic paper, Barber and Fox ${ }^{2}$ discussed the independent discovery of a bizarre phenomenon by two scientists. Aaron Kellner and Lewis Thomas both found that injections of the enzyme papain caused the upright ears of rabbits to droop over their heads like spaniels'. At first neither could find an explanation for it. Both abandoned the search and Kellner never returned to it, even though he went on to use the floppy ear response as a technical assay for measuring the potency of papain samples.

Lewis Thomas did look into it again and discovered that papain completely altered the structure of the matrix of cartilage, not only in the ears but everywhere else in the animal as well. Both Thomas and Kellner had originally missed these changes because they had assumed that cartilage was a stable and uninteresting tissue. Barber and Fox concluded that Thomas persisted with the problem because it played a role in his developing research while the floppy-eared phenomenon was irrelevant to Kellner's interests. Barber and Fox hinted that more personal factors were involved as well, a theme expanded by Thomas in a later autobiographical essay. ${ }^{3}$ Thomas had found the collapsed ears amusing. He claims this was the fundamental reason why he continued to keep an eye on the problem and quickly took it up again when events in another part of his research programme re-aroused his interest.

\footnotetext{
* Nicholas Russell, PhD, Nuffield Curriculum Projects Centre, 17 Rathbone Street, London W1P IAE

I am grateful to the Wellcome Trust for the award of a Research Leave Fellowship.

' W. F. Ogburn and D. S. Thomas, 'Are inventions inevitable', Political Sci. Q., 1922, 37: 83-98; R. K. Merton, 'Priorities in scientific discovery', Am. sociol. Rev., 1957, 22: 635-59; 'Singletons and multiples in scientific discovery. A chapter in the sociology of science', Proc. Am. Philos. Soc., 1961, 105: 470-86; 'Resistance to the systematic study of multiple discoveries in sciences', Eur. J. Sociol., 1963, 4: 237-82; A. Brannigan and B. A. Wanner, 'Historical distribution of multiple discoveries and the theories of scientific change', Soc. Stud. Sci., 1983, 13: 417-35; D. Lamb and S. M. Easton, Multiple discovery, the pattern of scientific progress, Avebury, 1984; D. K. Simonton, Scientific genius: a psychology of science, Cambridge University Press, 1988, ch. 6, 'Multiple discovery and invention'.

2 B. Barber and S. Fox, 'The case of the floppy-eared rabbits; an instance of serendipity gained and serendipity lost', Am. J. Sociol., 1958, 64: 128-36.

${ }^{3}$ L. Thomas, The youngest science, Oxford University Press, 1984, ch. 14.
} 
Kellner apparently had a more serious cast of mind. He was rather put off further investigation of floppy ears just because they were amusing and therefore, to him, essentially trivial.

This example demonstrates that analysis of the circumstances surrounding independent discoveries can lead to some understanding of how and why scientists originate fresh ideas and craft new facts. Another case is developed below, where autobiographical accounts together with the published record allow some tracking of the pathways along which different individuals arrived at the same conclusion. Here it is possible to argue that the contexts in which the protagonists made their discoveries reflected differences in their scientific research styles which may, in turn, have derived from differences between their personalities and cognitive histories.

\section{THE DISCOVERY OF MONOAMINE OXIDASE (MAO)}

The enzyme monoamine oxidase is widely distributed in all mammalian tissues and has at least two functions. It destroys toxic amine molecules generated by intestinal gut flora or endogenous metabolism and it is also responsible for oxidizing several synaptic neurotransmitters, thus terminating their action. The enzyme is inhibited by a wide variety of chemicals (monoamine oxidase inhibitors) which interfere with its action. In the brain, this leads to elevated levels of neurotransmitter which produce mood changes. Monoamine oxidase inhibitors have therefore been widely used as anti-depressants and the study of the mechanism of their action has been important for the development of pharmacological science. ${ }^{4}$ The clinical importance of MAO inhibitors was not discovered until decades after the enzyme had been first characterized. Therefore, hindsight has rendered this discovery historically significant, although only one aspect of the enzyme's function, the oxidative breakdown of adrenaline, was seen as important at the time, and it was this which helped to accelerate the career of one of the discoverers.

In the introduction to a conference on monoamine oxidase in 1978, the pharmacologist Von Korff remarked, "This year marks the fiftieth anniversary of the discovery of monoamine oxidase by Mary Hare Bernheim". 5 This statement has an element of truth since Hare Bernheim was certainly the first person partially to isolate and characterize what later came to be called monoamine oxidase. She called her enzyme tyramine oxidase since she detected only one of its localized actions, the detoxification of one amine metabolite. ${ }^{6}$

Another particular aspect of monoamine oxidase function was established nearly ten years later in 1937 by Blaschko and his colleagues as adrenaline oxidase. ${ }^{7}$ Soon afterwards, Quastel and Pugh published evidence for the existence of a widely distributed tissue enzyme responsible for the breakdown of aliphatic amines, another partial characterization of aspects of monoamine oxidase function. ${ }^{8}$ Later in the same year, Blaschko and Quastel independently arrived at the conclusion that these various functions were the effects of a

\footnotetext{
${ }^{4}$ G. J. Siegal, R. Wayne Albers, B. W. Agranoff and R. Katzman (eds), Basic neurochemistry, (3rd ed.), Boston, Little, Brown and Co, 1981, 747-8.

${ }_{5}^{5}$ T. P. Singer, R. W. Von Korff and D. L. Murphy (eds), Monoamine oxidase. Structure, function and altered states, London, Academic Press, 1979, p. 1.

${ }^{6}$ Mary L. C. Hare, 'Tyramine oxidase 1. A new enzyme system in liver', Biochem. J., 1928, 22: 968-79.

${ }^{7}$ H. Blaschko, D. Richter and H. Schlossmann, 'The inactivation of adrenaline', J. Physiol., 1937, 90: 1-19.

${ }^{8}$ C. E. M. Pugh and J. H. Quastel, 'Oxidation of aliphatic amines by brain and other tissues', Biochem. J., 1937, 31: 286-91.
} 


\section{Nicholas Russell}

single enzyme, an amine oxidase capable of oxidizing a wide range of both aliphatic and aromatic amines, ${ }^{9}$ although Quastel's paper contained no mention that adrenaline was one of its substrates, despite Blaschko's prior publication of this fact in a widely read journal.

Blaschko's and Quastel's papers arrived at the offices of the Biochemical Journal within a day of each other and were published in the same issue. There was a near-simultaneous emergence of the concept that mammals possessed a widelydistributed, wide-spectrum, amine-oxidizing enzyme, an idea elaborated from previous suggestions and partial characterizations.

In 1937 Quastel was 38 years old and had been leading a small biochemical research team attached to Cardiff City Mental Hospital since 1930, while Blaschko, a year younger, had been working in Joseph Barcroft's Physiology Laboratory at Cambridge since 1934. Quastel's route to Cardiff had been from a small shop-keeping background in Sheffield, via a scholarship to the local grammar school, a spell in a Public Analyst's laboratory and as a pathology technician in the wartime Medical Service, to a degree in chemistry at Imperial College, taken in 1921. He then undertook $\mathrm{PhD}$ research in Gowland Hopkins' Cambridge Biochemistry Laboratory and in 1924 was elected to a five-year fellowship at Trinity College. He left Cambridge for Cardiff in $1929 .^{10}$

Blaschko was born and raised in Berlin, the son of an eminent dermatologist. He graduated in medicine in 1922, undertook intern posts until 1924 and then obtained a research assistant position with Otto Meyerhof at Dahlem. He spent an unhappy year as assistant professor of physiology at Jena before Meyerhof offered him a salaried position in 1929. He spent another training year at A. V. Hill's University College laboratory in London before getting under way with Meyerhof in 1930. Both this position and his previous posts were seriously disrupted by recurring pulmonary TB. In 1933, when the Nazis took power, Blaschko left Germany for good, spending another year in London with Hill, before finally setting up as a researcher in his own right at Cambridge in 1934. ${ }^{11}$

According to his own accounts, Blaschko's pathway to the discovery of amine oxidase was reasonably short and straight. ${ }^{12}$ On arrival at the Physiology Department in Cambridge he unpacked his Warburg manometers and began looking for a research topic on which to use them. In England before the early 1930s, all manometry had been done with Barcroft apparatus, Joseph Barcroft, with J. S. Haldane, having more or less invented the technique in 1902. Quastel had left Cambridge for Cardiff before either Krebs or Blaschko arrived there with their Warburgs and he continued to use Barcroft apparatus until 1937 , before he too swapped over.

${ }^{9}$ C. E. M. Pugh and J. H. Quastel, 'Oxidation of amines by animal tissues', Biochem. J., 1937, 31: 2306-2321; and H. Blaschko, D. Richter and H. Schlossmann, 'The oxidation of adrenaline and other amines', Biochem. J., 1937, 31: 2187-93.

${ }^{10}$ Details of Quastel's background and role in the MAO discovery are taken from J. H. Quastel, 'A short autobiography', Comprehensive biochemistry, eds. Albert Neuberger, Laurens L. M. van Deenen, vol. 35 , Selected topics in the history of biochemistry, Amsterdam, Elsevier, 1983, pp. 129-87; '50 years of biochemistry. A personal account' Can. J. Biochem., 1984, 52: 71-82; and 'Interview with Professor J. H. Quastel FRS' by Professor Harry Bradford, Imperial College, London, Biochemical Society Video Archive, July 1983.

"'Details of Blaschko's background and role in the MAO discovery are taken from H. Blaschko, 'A biochemist's approach to autopharmacology', in Neuberger and Laurens, op. cit., note 11 above, pp. 189-231; 'My path to autopharmacology', Annual Rev. Pharm. Toxicol., 1980, 20: 1-14; and 'Interview with Professor H. K. F. Blaschko FRS' by Professor Peter Banks, University of Sheffield, Biochemical Society Video Archive, September 1988.

${ }^{12}$ Blaschko, 'My path to autopharmacology', op. cit., note 11 above. 
For his first project in Cambridge Blaschko used his manometers to study the kinetics of the enzyme catalase and its inhibition, but he was still casting about for a better problem. Chance soon provided one. Since he worked in the laboratory next to Barcroft and was using the latest manometric technology, Barcroft was much interested in the apparatus and in Blaschko's results. Barcroft used to show Blaschko results in return. A warm professional friendship developed between the youngish tyro and the professor. One day, probably early in 1935, Barcroft casually asked Blaschko how adrenaline was destroyed, as a footnote to some work upon which he was engaged. Blaschko did not know but promised to go and look it up. To his surprise, despite the long research history of adrenaline, he found that no one knew how it was destroyed in vivo, although it was readily auto-oxidizable in vitro. It was assumed that this accounted for its biological degradation as well. That seemed to Blaschko unsatisfactory and he therefore began to investigate the matter. ${ }^{13}$

Blaschko has recorded that his decision to engage with this problem was influenced by two factors. First, he had already done work on auto-oxidation with Meyerhof ten years before. He guessed there might be parallels between this earlier auto-oxidation work and the in vitro auto-oxidation of adrenaline which he could exploit. Second, he was sharing a laboratory with Hans Schlossmann, recently arrived as a refugee from Germany, who was an expert on bioassays. Since adrenaline concentration could only be determined by bioassay (using rabbit intestine contraction or cat blood-pressure), he needed such expertise to estimate adrenaline concentration. Together with another refugee from Fascism, the chemist Derek Richter, introduced to Blaschko by Krebs as someone else who was interested in the oxidation of adrenaline and who was working with Hopkins in the Biochemistry Laboratory, they began to look carefully at the conditions of biological adrenaline breakdown.

In a paper submitted for publication in December 1936 Blaschko's team concluded that its breakdown was compatible with the existence of a widely distributed, cyanideinsensitive, adrenaline oxidase enzyme. ${ }^{14}$ They quickly moved on to see whether the same experimental conditions would lead to the breakdown of noradrenaline and dopamine (they did), and then elaborated the substrate range further, generalized the behaviour of their enzyme system as an amine oxidase in a second paper submitted almost a year later, early in November 1937. ${ }^{15}$ At publication they were able to take account of Quastel's results on aliphatic amines and had learned, through Richter in the Biochemistry Laboratory, about Hare Bernheim's earlier work on tyramine oxidase, which had been carried out under Hopkins' supervision. Similar substrates, all being metabolized in a similar way, pointed clearly to the operation of a common enzyme.

The pathway towards Quastel's (and Pugh's) 1937 papers on amine oxidase was more tortuous. ${ }^{16}$ When he arrived at Cardiff in 1930 Quastel took some time to find his feet, since he had no previous experience of brain biochemistry, or knowledge of psychiatry and mental disorder. To begin with he followed up work on the respiratory metabolism of

\footnotetext{
1.3 Ibid.

${ }^{14}$ Blaschko et al., op. cit., note 7 above.

is Blaschko et al., op. cit., note 9 above.

${ }^{16}$ Quastel, 'A short autobiography', op. cit., note 10 above.
} 


\section{Nicholas Russell}

succinate which he had begun in Cambridge. He found that the respiratory metabolism of brain and muscle were the same, and went on to show that glucose was the main respiratory substrate of the brain in vitro. However, since his clinical colleagues were sceptical that brain chemistry could make any contribution to the biology of mental disease, he needed to find a biochemical project which had more direct bearing on problems of brain malfunction. In discussions with clinical colleagues and on ward rounds, he had been impressed by a treatment in which patients were induced into lengthy periods of sleep, and thus minimal brain function, with barbiturates. He set about looking at the effect of barbiturates on animal brain in vitro and found that they strongly inhibited glucose metabolism, but not by the mechanism of general respiratory poisons. These results were published in $1932 .{ }^{17}$

Quastel claimed to have developed a line of thought with a long productive life from this work. He felt that since agents like barbiturates could cause symptoms of mental illness as well as sometimes lead to successful treatment, there might be internally generated "barbiturate-like" molecules which, if produced in excess, could be the cause of some neurological diseases. That apparently led him to consider whether amines, either break-down products of amino acids or gut-absorbed toxins, could depress brain glucose metabolism in the same way as barbiturates. In 1933 he published results showing that amines produced by the breakdown of tyrosine, tryptophan and iso-amylamine could indeed suppress brain glucose metabolism in the same way as barbiturates. ${ }^{18}$

If it was true that an excess of such naturally occurring amines might affect mental behaviour, it was likely that they would be rapidly broken down and detoxified. By the end of 1936 he and Mary Pugh submitted a paper showing that brain and other tissues did metabolize simple aliphatic amines rapidly by deamination, suggesting the existence of an aliphatic amine oxidase enzyme which could detoxify some of them. ${ }^{19}$ At the end of October 1937 they submitted another paper showing that this enzyme also oxidized various aromatic amines including tyramine. ${ }^{20}$ By this time they had also come across Hare Bernheim's paper and were pretty sure that her tyramine oxidase was the same as their more general amine oxidase. Thus Quastel and Pugh had arrived at the same conclusions as Blaschko, Schlossmann and Richter.

How Mary Hare Bernheim became involved with the initial discovery of the tyramine oxidase in the late 1920s is unclear. Under her maiden name of Mary Hare, she carried out her research as a supervised project with Hopkins in the Cambridge Biochemistry Laboratory while she was Bathurst student at Newnham College. Previous work had shown that tyramine was a gut-flora generated toxin which was oxidized in the liver and also produced adrenaline-like effects. Mary Hare investigated the effects of tyramine on oxygen uptake in tissue extracts and found that oxygen consumption went up while tyramine deamination occurred at the same time. No established enzyme seemed likely to be able to catalyse such a reaction. She therefore proposed that this liver oxidation of tyramine was catalysed by an enzyme not previously characterized. Her first paper was

${ }^{17}$ J. H. Quastel and A. H. M. Wheatley, 'Oxidations by the brain', Biochem. J., 1932, 26: 725-44.

ix J. H. Quastel and A. H. M. Wheatley, 'The effects of amines in oxidations of the brain', Biochem. J., 1933, 27: 1609-13.

${ }^{19}$ Pugh and Quastel, op. cit., note 8 above, pp. 286-91.

20) Pugh and Quastel, op. cit., note 9 above, pp. 2306-2321. 
published in 1928. ${ }^{21}$ She then became a research fellow at Newnham and extended the observations on her putative enzyme. ${ }^{22}$ By then she had married an American, Bernheim, who was working in the same laboratory with Malcolm Dixon on the nitrate metabolism of liver. At this point she seemed to disappear from Cambridge science and produced no more publications on amine oxidizing enzymes.

\section{DISCUSSION}

This can only be a provisional account of events surrounding the discovery of wide-spectrum amine oxidase. It was a minor component in the construction of the outline of mammalian metabolic biochemistry in the 1930s. It can be explored in a little depth because the two protagonists went on to establish major reputations (both became FRS) and have been asked to record their memories. Both chose to go into some detail about this episode because of the later significance of monoamine oxidase and its inhibitors in clinical psychology. They have both been credited with discovering this original fact. It has not led to any dispute over priority because of the simultaneous arrival of their papers for publication in the same journal. Shared laurels were the only possible outcome.

Accounts given by participants of events which occurred a long time ago are subject to many obvious practical limitations. ${ }^{23}$ One school of sociology of science goes further and argues that scientific discovery accounts are distorted by the continuous process of constructing a practitioners' history of their discipline. Past events are interpreted in the light of the state of scientific knowledge at the point when descriptions of earlier events are given. ${ }^{24}$ Overlying this mythologizing process is the tendency for scientific terms to change meaning and for the earlier, loose and sometimes contradictory meanings, to be ignored. Accounts of past events are described using the terms in their current sense, thus producing a further layer of distortion. ${ }^{25}$ Also lost from individual accounts are interactions with colleagues. Testimony drawn only from leaders allows them to give the impression that they alone were the sources of innovative thought and action, and it loses much of the richness of day-to-day events in the messy research process. ${ }^{26}$

In the light of these difficulties, historians are sometimes counselled to give up trying to recover "what actually happened" and psychologists are encouraged to abandon the lingering concept of the individual "genius", whose powers of creative insight alone shape scientific events. While it would be foolish to ignore any of the traps lying in wait for the unwary scholar, neither historians nor psychologists are obliged to abandon their own objectives. Historians are entitled to keep on trying to understand, however partially, how and why concrete events took place. I therefore intend to tease out some speculative conclusions of a realist nature about the personal scientific behaviour of Blaschko and Quastel, aware that the evidence is open to a range of alternative interpretations.

\footnotetext{
${ }^{21}$ Hare, op. cit., note 6 above.

22 Mary L. C. Bernheim, 'Tyramine oxidase 2. The course of the oxidation', J. Biol. Chem., 1931, 93: $299-308$.

${ }^{23}$ N. C. Russell, 'Towards a history of biology in the twentieth century: directed autobiographies as historical sources', Br. J. Hist. Sci., 1988, 21: 77-89.

${ }^{24} \mathrm{~S}$. Woolgar, 'Writing an intellectual history of scientific development: the use of discovery accounts', Soc. Stud. Sci., 1976, 6: 395-422; N. Gilbert and M. Mulkay, 'Experiments are the key. Participants' histories and historians' histories of science', Isis, 1984, 75: 105-25.

${ }_{25}$ Ilana Löwy, 'Variances in meaning in discovery accounts; the case of contemporary biology', Hist. Stud. Phys. Sci., 1990, 21: 87-121.

${ }^{26}$ B. Latour and S. Woolgar, Laboratory life: the social construction of scientific facts, Sage, 1979; G. L. Geison, 'Scientific change, emerging specialities and research schools', Hist. Sci., 1981, 19: 20-40.
} 


\section{Nicholas Russell}

Firstly, it seems clear that the concept of amine oxidase arrived at by both parties was essentially the same. There is not the added complexity of doubting whether the discoveries were actually the same because the social or intellectual frameworks in which they were expressed were different. ${ }^{27}$

Secondly, nobody was looking for such an enzyme as a consequence of testing a pre-conceived hypothesis. On the other hand, neither was its discovery an example of serendipity. Both Blaschko and Quastel were pursuing programmes in which the discovery of several, local, amine-breaking enzymes was a possible outcome.

Thirdly, the two discoverers shared a large number of factors in common. Both Blaschko and Quastel were working in England within the same discipline, biochemistry, on the smallish area of biological oxidation of amines, using a widely-employed technique, manometry, applied to standardized tissue preparations. Yet the context of discovery in the two cases was very different. The same outcome was stamped with evidence of separate frameworks of personal interest, psychological approach and accidents of cognitive history.

For instance, secondary differences in methodology reflect the different backgrounds of the players. Quastel's basic training in analytical chemistry and his strategic objective of seeking widespread amine breakdown, governed his choice of product assay and his method for doing it. He measured the concentration of ammonia accumulating from oxidative deamination. To do this effectively on a micro-scale, he had to refine considerably a chemical procedure devised by François at the turn of the century. Together with Mary Pugh, he published a separate paper describing this technique. ${ }^{28}$

Blaschko was investigating adrenaline breakdown and he had few preconceived ideas about how this occurred. It therefore made sense to measure adrenaline breakdown directly. His wide experience of physiological and biochemical procedures had familiarized him with the principles of the necessary bioassay. Once he had established that adrenaline was broken down by an oxidative enzyme system, and wished to generalize the reaction to other substrates, his lack of background in analytical chemistry proved a disadvantage. In moving to other catecholamines, and then amines in general, he had to monitor the oxidations from oxygen uptake alone.

More significant than these minor methodological variations are the different research programmes from which the wide-spectrum amine oxidase concept emerged. These differences, in turn, hinged on accidents of career development and on differences in research style. Quastel's and Blaschko's autobiographies, if taken at face-value, suggest such contrasting styles. Critics might argue that the differences in attitude towards life in research, and to scientific problems, which emerge from these accounts are a consequence of different conventions of self-presentation. These could result from their contrasting class backgrounds, and upbringing and education in different countries. However, it is also possible that these class and nationality differences were responsible for real differences in their scientific behaviour. Taking the autobiographical accounts at face value shows up interesting contrasts which seem to resonate with how the separate discoveries of amine oxidase were made.

${ }^{27}$ T. S. Kuhn, 'Historical structure of scientific discovery', Science, 1962, 136: 360-64.

${ }^{28}$ C. E. M. Pugh and J. H. Quastel, 'Micro-determination of ammonia in the presence of aliphatic amines', Biochem. J., 1937, 31: 282-5. 


\section{Independent discovery in biology}

Blaschko began his research apprenticeship in Otto Meyerhof's Dahlem laboratory in 1925. Meyerhof (with A. V. Hill) had won the Nobel prize for Physiology and Medicine in 1922 , for work on the mechanism of muscular contraction. In 1925, therefore, a position in Meyerhof's laboratory was much sought after. But when Blaschko applied to work with Meyerhof in 1925 he had scarcely heard of him. Blaschko relied on the network of influential scientific friends of his distinguished medical father. The well-placed mathematician Richard recommended Blaschko for an unpaid position with Meyerhof, after Blaschko had failed to find any research position for himself.

For the next ten years Blaschko published very little. He did write up the results of his first project with Meyerhof, on cyanide inhibition of auto-oxidation reactions, which he later picked up when he finally started as an independent researcher in Cambridge. The auto-oxidation work in 1925 seems to have been a piece of make-work, allocated by Meyerhof, although it actually fell within Warburg's research ambit. As a former student of Warburg, Meyerhof was still engaged on one or two bits and pieces springing from that association. Blaschko was just about the last person in Meyerhof's laboratory to work on Warburg-determined themes. The only other piece of work which led to a significant publication was a project undertaken at the Plymouth Marine Station in 1930, during a training year he spent in England with A. V. Hill (at Meyerhof's insistence). ${ }^{29}$ Otherwise he mucked in with the main project in Meyerhof's laboratory, anaerobic respiration reactions in muscle using cell-free extracts. He became thoroughly versed in a wide range of techniques and contributed to the published work of several of his colleagues. He also made a large number of influential scientific friends but suffered a number of severe bouts of pulmonary tuberculosis. When his Continental career was rudely disrupted in 1933, he was able to come straight to England and spent another year with A. V. Hill, working for the Academic Assistance Council, set up that year to help refugee scholars settle in England. Barcroft's casual question about adrenaline breakdown at last sent him off down a productive track whose ramifications occupied the rest of his career. Having solved the problem of adrenaline breakdown and found, as a side issue, that the enzyme concerned was a generalized amine oxidase, Blaschko spent the rest of his research life, first in Cambridge and then at Oxford (moving to the latter university in 1944), always working on aspects of the synthesis, breakdown and functions of catecholamines.

According to his own testimony, Quastel's apprenticeship in science was a much more deliberate process. Quastel actively sought experience as a public analyst's assistant in Sheffield when he had left school and quickly responded to a plea to train as a bacteriological technician in the pathology service, after he was called up in the First World War. (Blaschko also did technical work as part of the war effort, on the other side, after graduating early from school. Characteristically, he said that his post, food-testing at an agricultural institute, was found for him by his father.)

After graduating in Chemistry from Imperial College in 1921, Quastel turned down a good offer of employment in the Colonial Service (which others from a similar

\footnotetext{
${ }^{29} \mathrm{H}$. Blaschko, 'Uber den Mechanismus der Blausaurehemmung von Atmungsmodellen', Biochem Z., 1926, 175: 68-78; H. Blaschko, McK. Cattell, J. L. Kahn, 'On the nature of the response in the neuromuscular system of the crustacean claw', J. Physiol., 1931, 73: 25-35.
} 
background in the same situation decided they could not afford to do $)^{30}$ and applied for a studentship in Cambridge because he had heard of Gowland Hopkins and liked the sound of what he was doing. Somewhat to this surprise he was successful and stayed in Cambridge until 1930, first as a doctoral student and then as a research fellow. In contrast to Blaschko's apprenticeship experience, Hopkins provided no guidance as to what Quastel should do for his thesis; he had to find his own problem. He began investigating fumarate and succinic metabolism in bacteria and by 1924 was able to demonstrate the bacterial oxidation of fumarate to pyruvate, a piece of work which established his reputation at a time when the intermediary metabolism of respiration was a subject of very widespread research (as indeed it was in Meyerhof's laboratory, although perhaps significantly, Blaschko did not make any major contribution to the topic in the 1920s).

Further quantitative work with fumarate and succinate metabolism convinced Quastel that all bacterial oxygen uptake could be accounted for by respiratory demand and he therefore wondered how bacterial growth could take place if there was no oxygen "left over" to account for it. He collaborated with Margaret Whetham in work on resting and proliferating bacterial cells, developing the liquid culture of $E$. coli as an experimental system. This allowed Quastel and Whetham to expand greatly their observations on bacterial metabolism. By the late 1920s Quastel had developed some abstract theoretical ideas about how respiratory enzymes might work, through some kind of "active centre", a notion which apparently found little favour with Hopkins or his other colleagues. This, among other things, tempted him to apply for a post away from Cambridge. Again, he did this for himself, not relying on any network. Hopkins was mildly surprised that he should have thought of applying for the post of biochemist at Cardiff Mental Hospital. However, he did receive MRC backing for his application; it was suggested that he would receive funding to work on brain biochemistry if his application was successful. He left Cambridge with twelve published papers already to his name, a record of independent action and independent thought, and a taste for speculative theorizing about the fundamental mechanisms of biochemical action in cells and tissues.

In Cardiff, Quastel began searching for biochemical bases for brain malfunction. One component of this search was his theoretical idea that barbiturates might have internal molecular mimics. His demonstration of amine oxidase arose from testing this analogical hypothesis. Blaschko's came from solving a local puzzle about the biodegradation of a significant hormone molecule. Quastel was engaged in a more sophisticated enterprise, several years into a complex programme, and with previous experience of elaborating abstract theories.

Quastel made an early reputation because of his bacterial respiratory work at Cambridge, but he suffered something of a setback once he began to move into an area of abstract analysis. His publications on mental disorders continued to leave him, at that time, outside the mainstream of elite biochemical interests. By contrast, in 1937, it was Blaschko's turn to have the good fortune to be in fashion. The significance of catecholamines as humoral neurotransmitters was just emerging. His publication on

\footnotetext{
${ }^{30}$ N. C. Russell, 'The history of biology through reminiscence', Biologist, forthcoming; Institute of Biology History Group questionnaire responses of Robert J. Lever and Walter W. Mayne.
} 
adrenaline oxidase made him instantly noticed. At the time, the separate amine oxidase publications by Blaschko and Quastel probably caused little stir, compared with the papers with which they made their initial reputations.

The differences between the independent discoveries of amine oxidase can be interpreted in terms of the differences in personality and research style between the protagonists. Early on, Blaschko had only limited ability to initiate research problems. He responded to suggestions laid down by others, most of which, for a variety of reasons, did not lead anywhere interesting. When he did find a programme with significant implications, it was once again in response to someone else's question. The problem he set himself was straightforward and local (although that did not guarantee that the outcome was going to be simple). In practice, the solution to the first problem came quickly and suggested further puzzles for solution. The discovery of amine oxidase was one, unexpected, outcome of the development of a branching pathway of problems.

Quastel's background and personality seem to have led him to devise problems for himself at a much earlier stage of his career. Independent problem-seeking was both forced on him by Hopkins' non-directive style of supervision and was in tune with his personality. Almost from the beginning he seems to have chosen problems with wide-ranging implications and to have developed early a taste for abstract speculation, using metaphorical argument and developing ideas with cascades of testable consequences linked together by long chains of inference. This pattern had emerged with his enzyme-behaviour speculations while he was still at Cambridge, and was honed with his multiple programme at Cardiff, of which the work leading to amine oxidase was merely one part. There is evidence from his subsequent career that Quastel continued to indulge this taste for moving into new areas where he could exploit his powerful device of thinking through metaphor.

Providing a firmer support, in these two cases, for this suggested link between career development, style in scientific research, personality and personal history, would need an extensive analysis of the rest of their careers and probably more archival information than is available. It may also be true that the sharp differences in the context of this discovery of amine oxidase were the results of the different stages that the two had reached in their own careers. Blaschko had only just begun to work on his own problems in 1937, while Quastel had been a wholly independent operator since at least 1924, when he completed his $\mathrm{PhD}$. This is certainly an additional factor contributing to the differences between their pathways to this discovery. Nonetheless, enough has emerged to suggest that exploration of further episodes of independent discovery together with investigations of individual research style are worth pursuing in the study of discovery processes. 